\title{
INTRODUCTION
}

\section{Bridging the Gap}

\author{
Wouter Veraart
}

Last year we have had a fruitful public discussion on the course of NJLP in coming years. The outcome of this discussion has been that NJLP will remain a journal with a double aspiration. On the one hand, we will continue to be a peer reviewed journal with a solid and visible presence in the international arena. On the other hand, we aim to stay in tune with legal practice in the Netherlands and Belgium, and will offer a place for legal philosophical and legal theoretical reflection with direct relevance for legal practitioners and current legal, societal or political debates.

This renewed double aspiration means that we have implemented a few changes. As of 2017, we will in principle publish two issues each year, one normal issue based on peer reviewed submissions, and one special issue. The annual special issue will be alternating between an international special issue around the work of a renowned legal philosopher, and a societal special issue, taking a legal philosophical or legal theoretical angle on themes with a particular relevance today.

In addition, our publisher allows us to remain flexible, enabling us to publish more issues if needed, and offering the possibility of early online publishing of fully accepted articles on the NJLP-website.

This mission of NJLP, which may be summarized as bridging the gap between 'international' legal philosophy and 'local' practice, suits her very well. In fact, the gap between the 'universal' and the 'local' is reminiscent of Paul Scholten's famous gap between the general norm and the legal verdict in the concrete case, a problem very much at the core of legal philosophy itself.

As always, the editorial board of NJLP is looking forward to fulfill its ambitions in coming years and hopes that you will enjoy the first issue of 2017. 